\title{
Community participation in international health: practical recommendations for donor and recipient organizations
}

\author{
Chinua Akukwe ${ }^{1}$
}

ABSTRACT This article discusses the need for donor agencies and recipient organizations to involve target communities in the conceptualization, development, monitoring, and implementation of health services and programs in international health. This paper assumes that most donor organizations are based in industrialized countries. Given that resources are finite in both developing and developed countries, the article briefly reviews the current trend of declining public funds for health systems and an increasing role for privately funded health services worldwide. The article calls for community-based international health services that reflect the priorities of target populations, and it also discusses practical steps to involve local populations in community-based health planning and management in international health.

International health refers to health relationships between nations. Countries relate to each other on many issues, including health, defense, trade and commerce, diplomacy, and education. Nations also relate to each other through such United Nations agencies as the World Health Organization (WHO), the United Nations Children's Fund (UNICEF), and the United Nations Educational, Scientific, and Cultural Organization (UNESCO), to mention only a few. Nations also "trade" in health services, by "exporting" health services that they have in abundance or for which they have some comparative advantage, or "im-

\footnotetext{
1 George Washington University, School of Public Health and Health Care Sciences, Washington, D.C. Mailing Address: Dr. Chinua Akukwe, P. O. Box 66621, Washington, D.C. 20035-6621. Email: CAKUKWE@compuserve.com
}

porting" services that they need or cannot produce in sufficient quantities for their citizens (1).

"Community participation," according to the Pan American Health Organization (PAHO), is a process that ensures the active participation of community members in programs or other efforts that are conducted in their interest (2). PAHO identifies three distinct levels of community participation: the utilization of services by the target community, the "cooperation" of the local community in foreign-funded programs, and community participation in the planning and management of health activities (2). For the purposes of this paper, community participation in international health is defined as a process of guaranteeing that target communities take an active role in the conceptualization, design, implementation, and evaluation of externally funded programs designed in their interest and reflective of their health priorities. If followed, this process ensures that the felt needs of target communities are given considerable attention before external funding for health services is approved. It also makes community participation in health services an important national health policy, especially in externally funded programs.

In the current state of health relationships between nations, certain distinct trends are evident (3-5). First, because of their socioeconomic circumstances, developing countries rely on industrialized countries for fiscal and technical support in health services. The socioeconomic profile of developing countries, including those in Latin America and the Caribbean, suggests that social and economic inequities will continue to be long-term chal- 
lenges. Second, nongovernmental organizations (NGOs) are very active in international health and provide services to indigent populations in developing and developed countries. Third, publicly funded health systems are in decline worldwide and privately funded health services are steadily increasing $(3,4)$. Fourth, in Latin America, the Caribbean, and other parts of the developing world, the call for local involvement in developing health priorities and managing health services in international health is well known (2-4). Fifth, as socioeconomic problems increase in industrialized societies, their governments and the NGO movement are under growing pressure to focus on their own citizens, rather than on persons overseas $(6,7)$. Finally, the United States of America, a major donor country, is critically reviewing the social programs for its vulnerable citizens and "reforming" these programs, as shown by the recent welfare legislation and its mandate to cut off benefits after two years for those who "can" work (8).

This paper discusses the need to involve target communities in developing and managing health services and international health programs. The fundamental assumption in the paper is that resources, especially financial ones, are finite in both developed and developing countries and thus must be used very effectively. This paper focuses on the role of donor agencies (mostly from industrialized countries) and recipient organizations (mostly operating in developing countries, such as those in Latin America) in ensuring the participation of local communities in the conceptualization, design, implementation, and evaluation of health programs. Finally, this article presents practical steps to involve local populations in community-based health planning and management of international health activities.

\section{THE STATE OF HEALTH IN THE AMERICAS}

According to PAHO (9), health conditions in the Americas are marked by ongoing social inequalities across populations and an increasing proportion of individuals and communities living in poverty. Other issues that have affected the health conditions of the Americas include the rapid rate of urbanization, the armed conflicts of the 1980s and early 1990s, and continued unemployment for large segments of the population. Noncommunicable diseases account for nearly $60 \%$ of all deaths in the Americas, while communicable diseases and perinatal causes account for another $30 \%(3,4,9)$. Latin America and the Caribbean have the second highest rate of injuries (intentional and unintentional) in the world (4). The incidence of circulatory diseases, with their lifestyle risk factors, continues to rise in Latin America and the Caribbean, while declining in the United States and Canada.

Despite these problems, countries in the Americas recorded impressive strides in health between 1970 and 1992. The Region had declines in infant and early childhood deaths and general fertility $(3,4,9)$. The capacity of health systems in the developing countries of the Americas to provide needed services is superior to that of developing countries elsewhere (9). However, this capacity is not adequate for all those in need. The influence of privately funded health systems is growing in the Americas $(3,4,9)$. PAHO is actively involved in developing relationships and partnerships with other public sector agencies, such as the Inter-American Development Bank, to link economic growth with improvements in health.

In comparison to other parts of the developing world, the Region of the Americas is doing relatively better on health indicators $(3,9)$. In 1996, the average life expectancy, infant mortality rate, and under-five mortality rate were all better in the Americas than in Africa and Asia. Some two-thirds of the PAHO Member States, as well as the one PAHO Associate Member, Puerto Rico, met all three of the year 2000 health for all targets set by WHO in 1996 (these targets are a life expectancy at birth above 60 years, an under-five mortality rate below 70 per
1000 live births, and an infant mortality rate below 50 per 1000 live births). However, differences exist between countries in the Americas (3, 9, 10). Health status indicators in the United States and Canada are better than in Latin America and the Caribbean. Haiti remains one of the poorest countries in the world, with some of the worst health indicators of any nation. Additionally, differences in health status according to demographic and socioeconomic indicators exist in the Region $(3,4,10-13)$. For example, in the United States, ethnic minorities, rural residents, and low-income families have higher rates of infant mortality and are more likely to lack health insurance and to be on public assistance.

\section{EXTERNAL AID AND DEVELOPING COUNTRIES}

External aid generally flows from industrialized nations to developing countries. Also known as development assistance, this aid has never exceeded $0.30 \%$ of the combined gross national product of the industrialized countries $(4,6)$. In the United States, development assistance accounts for less than one-half of $1 \%$ of the federal budget (7). Further, in recent years, external aid has come under increasing scrutiny in industrialized nations $(4,6$, 7). The U.S. Agency for International Development (USAID) has recently had to vigorously defend its existence (7). This pattern is apparent in other industrialized countries as well (6). At the heart of this intense reexamination are two important issues: misconceptions as to the extent of external aid, and the growing proportion of citizens of industrialized societies who need government assistance. For example, according to USAID, Americans erroneously believe that external assistance accounts for nearly one of every five federal dollars (7). This perception is exacerbated by the growing numbers of Americans who either live in poverty or are not covered by health insurance. In 1996, 17\% of all Americans (44.8 million) had no health insurance (10). Nearly $25 \%$ of those 
without health insurance were children under 18 years of age. While 33\% of Hispanics and $23 \%$ of Blacks were uninsured, this was true for only $14 \%$ of the rest of the population of the United States (10).

These domestic developments in the United States are important signposts that deserve the close attention of international health leaders and advocates, for many reasons. First, politicians and policymakers understand that any "fight" on "behalf" of their local communities is a winner, anytime, anywhere. Second, improving the health status of local communities is consistent with the ideals of the worldwide public health movement, which recognizes the inherent capability of local populations to manage their health care based on priorities set locally $(2-4,9)$. Third, the best public health practices require the evaluation of programs to ensure that they meet stated goals and objectives $(3,4,6)$. Reaching community-based goals and objectives is particularly important in international health because donor organizations often focus on indigent and hard-to-reach populations (11). Finally, if other major donor countries adopt the policy of community-based development of international health priorities, funding for international health may change forever. The role of national health infrastructures or formal systems may be reduced as local communities take charge of their health services (11). Such a growing irrelevance of national systems could have major implications for $\mathrm{WHO}$, the World Bank, and other institutions that must rely on national infrastructures to meet their objectives.

\section{Pros and cons of community-based priority-setting}

Allowing local populations to define their problems and articulate possible solutions is a cherished ideal of public health. However, community health managers rarely achieve this goal in developed and developing countries, for varied reasons. First, local communities may not adequately articulate their health problems because of the influence of local customs and practices (2-4). For example, belief in traditional healers and in the knowledge of community elders may interfere with public health messages on health promotion and the prompt treatment of recognized medical conditions. Second, local communities may not have the human and material resources to address their health problems successfully $(2-4,9,11)$. Third, the health problems of poor communities may be unlike those of other, prosperous nearby communities. This situation is seen in the urban-suburban dichotomy in the United States (12), as well as in the urban-rural differences and the juxtaposition of shacks and luxurious homes in many cities of the developing world $(3,4)$. For example, while the rate of infant deaths in Washington, D.C., especially in the poor neighborhoods, is high, it may not be a serious priority for the neighboring states of Virginia and Maryland, which have significantly lower rates of infant deaths. Fourth, poor communities may depend heavily on external resources to provide health services, and external funding agencies and organizations may have their own goals and objectives $(6,11)$. Finally, poor communities may not have the political or economic sophistication to influence their national, regional, state, and local government priorities in health and human development $(5-7,11,12)$.

Nevertheless, allowing local communities to set health priorities has many advantages. These benefits include: ensuring that funded programs represent actual local problems and justify the use of scarce resources; incorporating the local community's nonhealth priorities, such as socioeconomic development and political representation, in the design of externally funded health programs; having the local community cooperate fully to meet program goals and objectives; assuring the sustainability of successful programs beyond the external funding cycles; and energizing local communities to begin the slow and tedious process of leveraging local resources, taking charge of their health problems, and eventually ending dependence on external assistance.

A fundamental and legitimate question is how to balance the need for "objective" assessment of community health needs with the "subjective" opinion of local communities $(2,5,6$, $11)$. For many reasons, the answer is not easy. First, as shown by the lack of community-level data in many developing countries, community-based projects often do not undergo the classic epidemiological process of needs assessment and quantitative and qualitative analysis $(2-5,9,11)$. Second, externally funded programs must rely on data available from host countries, even when it is outdated or inadequate $(4,6,11)$. Third, the process of obtaining "objective" or "subjective" opinions from the community may be considered expensive in the face of urgent health needs. Fourth, during a public health emergency, such as an epidemic or a natural disaster, the government has the legal obligation to act swiftly, without extensive consultation with the affected community. Finally, what will happen when the stated needs of the community run counter to accepted public health principles? For example, can a community exempt itself from an immunization program because the local residents do not assign high priority to a given disease?

Nevertheless, it is important that donor and recipient organizations pay attention to the opinions of their intended target populations. There are three principal reasons for this: official data on community health issues may be outdated or incorrect, the views of recipient organizations must be reconciled with the stated needs of the intended recipients, and for externally funded programs to be sustained, the target community must become involved in the planning of such programs and eventually develop a sense of "ownership."

\section{Developing sound local priority-setting}

Sound local priority-setting depends on accurate baseline data, but 
that information should go beyond birth and death statistics or hospitalbased data. It should include information on the knowledge, attitudes, and perceptions (KAP) of the target population regarding their health problems, their health status, and their personal and collective responsibilities toward dealing with identified problems $(3,4)$. Many local communities that need government assistance may not have the resources to produce accurate baseline data on their health problems. This can lead to a situation where local "leaders" or other activists articulate the views of local communities to external funding agencies and government institutions. Despite the good intentions of these community "experts," validated KAP studies are still vital in accurately assessing the felt needs of target communities $(6,11)$.

Local priority-setting in international health activities should be population based and should guarantee community participation in all phases of the process $(2,11)$. Each individual or family should have an equal chance of being chosen to speak or answer questions on their health status. Sampling frames and other procedures that give all people the opportunity to participate in priority-setting are important. Before surveys are conducted, priority-setting should include a comprehensive review of available data on the target population, from hospital records, past research activities, and government socioeconomic data. Baseline data should also include information on the culture and social organization of the target population, as well as the local economy, geography, and climate $(2-4,9,11)$. External funding agencies should share their findings from community-based surveys and retrospective data collection with the target communities. Open forums can provide feedback on additional issues not captured in the populationbased surveys.

Veteran community-based health practitioners know that national, regional, and state governments in developing countries have tremendous influence in the affairs of local commu- nities, despite the existence of district health systems $(3,4)$. The control of local health, economic, and political policies by national, regional, and state agencies has both positive and negative consequences. Beneficial outcomes include the introduction and application of uniform health policies, the development of quality assurance mechanisms and standards, the coordination of external relationships with such bilateral agencies as PAHO, $\mathrm{WHO}$, and USAID, and the possibility of equitable funding of health services. However, without being judgmental, involvement of target communities in developing local priorities may not be effective due to the huge bureaucracy associated with formal government services and policies. This can be true in both developing and developed countries $(2,4,6,11)$.

Thus, although district health systems are common in the Americas and elsewhere around the world, assuring the participation of local communities in setting health priorities is not easy. As noted by PAHO (2), major obstacles to community participation include hierarchical formal health systems with limited flexibility, a shortage of health personnel formally trained in community development and participation in health activities, and limited fiscal and human resources. Poor communities that cannot influence local, state, and national government policies may be in danger of having their health priorities go unrecognized by health policymakers and funding agencies $(4,11)$. For their part, national, regional, and state health planners and policymakers must make hard choices based on competing demands for health services. These decisions are even more difficult in the face of worsening health status and decreasing resources. The plight of these communities may also elude the attention of sympathetic external funding organizations that depend on published information and national data from the formal health systems of each country.

A two-pronged approach is needed to ensure community participation in national, regional, and state health systems, as well as in the design, imple- mentation, monitoring, and evaluation of externally funded health programs. Key elements of an appropriate methodology are addressed in the following two subsections.

\section{Community-based participation in national, regional, and state health systems}

Both short-term and long-term strategies are needed to guarantee community-based participation in national, regional, and state health systems. One short-term approach is to develop and implement federal guidelines and mandates on a minimum range of health and human services for vulnerable and high-risk populations in each country. These directives will establish specific health services that a sick individual must receive from the health care system, even when the delivery of health services is largely the responsibility of regional or state governments. For example, the standards might stipulate that each sick client should have a complete physical examination (including complete history of presenting complaints), urinalysis, stool analysis, and hemoglobin and white blood cell counts. Clients who are able to should pay for these services, but no one should be denied services. This minimum set of services could reveal much about ill persons and their families regarding anemia, diabetes, hypertension, intentional and unintentional injuries, cancers, pregnancy-related conditions, and other clinical conditions common in developing countries. Through the threat of enforcement and sanctions, national standards could ensure that vulnerable clients receive these services $(4,7)$. The medical and allied health professionals in each country would play a significant role in implementing this short-term strategy by developing pro bono programs and making participation in them a condition for initial licensure and license renewal. Mandatory programs that send newly qualified health professionals to serve one or two years in rural areas would help provide services to these isolated regions. 
A second short-term strategy is for national, regional, and state health systems to assure external funding agencies that proposed projects reflect local priorities. Such assurances should include a complete description of how priorities were identified, the rationale for choosing the location of the project, specific information on the role of the target communities, and benefits to local residents. Funding organizations should have the authority to verify the involvement of target communities. Donor agencies should not replace direct community involvement with "briefing papers" or guided tours of target communities, and they should establish mechanisms for direct contact with future program recipients to ensure that their views are considered.

A third short-term strategy is for the national, regional, and state health systems to implement a comprehensive outreach program for inhabitants of isolated areas. Health workers should visit these regions and provide services on a predetermined regular basis. Such visits will complement the efforts of community health workers (CHWs), who traditionally come from target locales. Nevertheless, it is important to recognize that, as noted by PAHO (2), CHWs may be seen as an extension of the hierarchical formal health system, rather than the "ears" and "eyes" of their communities.

A fourth short-term strategy should be to develop a national data collection and analysis mechanism that specifically incorporates regional and local differences in health status and also identifies major demographic, socioeconomic, psychosocial, and environmental correlates of poor health.

On a long-term basis, introducing a population-based democracy of one person, one vote can help lead to a nationwide consensus on major health, socioeconomic, and environmental issues (11). Democratic processes provide voters an opportunity to redress unjust policies and can help poor communities become active participants in policy-making. However, as shown in the United States and other developed countries, mobilizing disadvantaged groups is not easy $(11,12)$. For example, the worst health status and the lowest socioeconomic indicators are found in the poor neighborhoods of Washington, D.C., even though the city is the seat of the national government (12). Broader democracy should be coupled with genuine economic reform that promotes free enterprise but also protects the poor, disabled, and other disadvantaged segments of the society from the untoward effects of market economies $(1,3,4)$.

This author has deliberately omitted the issue of funding as a long-term strategy. The most effective way to improve health services funding is through population-based democracy and a vibrant private economic system that promotes economic self-determination but also recognizes the need for equitable distribution of resources. This is especially important given the decline in funds available to the public sector and the growing role of privately funded health services $(3,4)$.

\section{Local community participation in externally funded health programs}

Donor agencies should focus on ensuring the participation of local communities in setting health priorities, conceptualizing health programs, designing such programs, monitoring and modifying selected programs, and evaluating these programs. A recent PAHO document, the Annual Report of the Director 1996 (13), noted that national data-the international standard for health reports-may fail to reveal significant regional, state, and local health inequities. With their aggregate statistics, national data may also fail to reveal areas of greatest need. Donor agencies should always ask the following questions about a health program funding proposal:

1. Does the proposal address the identified local health priorities of the target community? Who determined the local health priorities? Who chose the proposed program? When, how, and where did individuals at risk of the described health condition participate in developing the proposal? Can the donor agency send representatives to the target community to evaluate the feasibility of the proposed program?

2. Does the proposal include specific information on the demographic, socioeconomic, cultural, psychosocial, political, and environmental concerns of the target community? Do any of these local concerns conflict with stated national or state policies?

3. What are the demographic, social, and economic relationships between proposed recipient organizations and the target community? What specific experiences and relationships do leaders of proposed recipient organizations have in the target community?

4. What are the specific roles of the target community in decision-making regarding the proposed program? Where will these decisions be made, that is, in the target community, the headquarters of the recipient organization, or in the donor agency offices?

5. Who will manage the proposed program once the external funding ends? Does the proposal include a sustainability plan? Did the target community participate in developing that plan?

6. Are there political difficulties in gaining approval for the project at higher levels of government? What are the policies of the national, regional, and state governments toward community-based organizations and externally funded community-based projects? Do government functionaries view community-based organizations as an extension of the government, a security threat, or a partner? What is the government position on the fiscal management of externally funded programs? What are the specific levels of government oversight of externally funded community projects?

By carefully reviewing the responses to these questions, donor agencies can become familiar with the political, so- 
cial, economic, and cultural dynamics of the target community, as well as its relationship with the government. These responses will also enable funding agencies to relate proposed funding goals and objectives to local health priorities and to analyze the potential for sustainability when external funding ends.

To facilitate this review and to ensure the participation of local communities throughout the funding cycle, this author believes donor agencies would be wise to follow the mandates given below for four key program areas: design, management, monitoring, and evaluation.

- Program design. Establish liaisons with recipient country, regional, and state governments to review program ideas and review national data and priorities; establish liaisons with local governments to review baseline data and priorities. Meet with local community leaders and activists to talk about health and other human services activities at the local level. Discuss KAP studies of target communities if available, and meet with ordinary members of the community to address their felt needs and priorities. Evaluate program design based on all levels of interaction and feedback, especially the opinion of the ordinary community residents. Develop specific guidelines for transition to local control at the end of the program's external funding cycle.

- Program management. Provide specific roles for target community members in program management. Employ local people as much as possible. Allow local residents to sit on national, regional, and district advisory boards. Have separate representation for community activists and other local residents. Ensure that critical program decisions are made only after consultation with the local community.

- Program monitoring/modification. Involve the target community in monitoring key program goals. Consult extensively with residents on changes in program objectives. Have specific mechanisms in place for direct local input or advice on the program.

- Program evaluation. At the beginning, put procedures in place so the program does not stall or become abandoned, a common occurrence in developing countries $(4,11)$. Include the residents of the target community in program evaluation. Disseminate the evaluation results to community members. Work with the local residents and the local and national government to develop specific policies based on the evaluation results. Work with the community to ensure a smooth transi- tion to local control at the end of the program's external funding.

\section{CONCLUSION}

The struggle for equity in health care is a major issue in international health $(2,3,13)$. Local inequities in health challenge both governments and the donor community. As PAHO has affirmed (13), clearly defining where inequities lie is an important first step in addressing their root causes. Involving target communities in developing and implementing health programs is key to recognizing the impact that health and nonhealth issues have on the health status of vulnerable groups. In the face of dwindling public sector dollars for health services and the growing influence of commercially driven health systems, donor agencies are important players in providing services to at-risk populations. Donors can work closely with the formal health system and the target communities to ensure that the health priorities of these communities are addressed and that local residents are eventually empowered to take charge of their health status.

There may be a silver lining in the intractable problem of health inequities if target communities participate actively in the development and provision of health services intended to protect their interests.

\section{REFERENCES}

1. Gomez-Dantes O, Frenk J, Cruz C. Commerce in health services in North America within the context of the North American Free Trade Agreement. Rev Panam Salud Publica 1997;1:460-465.

2. Pan American Health Organization. Community participation in health and development in the Americas. Washington, D.C.: PAHO; 1984. (Scientific Publication No. 473).

3. World Health Organization. World health report 1997-conquering suffering, enriching humanity. Geneva: WHO; 1997.

4. World Bank. World development report, 1993: investing in health. New York: Oxford University Press; 1993.

5. Mesa-Lago C. Health care for the poor in Latin America and the Caribbean. Washington, D.C.: Pan American Health Organization and Inter-American Foundation; 1992. (Scientific Publication No. 539).
6. Riddell R. Aid in the 21st century. New York: Office of Development Studies, United Nations Development Program; 1996.

7. U.S. Agency for International Development. Why foreign aid. Washington, D.C.: USAID; 1996.

8. Akukwe C. The potential impact of the 1996 welfare reform on intimate partner violence. Family and Community Health 1998;20:54-62.

9. Pan American Health Organization. Volume 1: Health conditions in the Americas. 1994 ed. Washington, D.C.: 1994. (Scientific Publication No. 549).

10. U.S. Department of Health and Human Services, Agency for Health Care Policy and Research. Health insurance status of workers and their families: 1996 research findings \# 2. Washington, D.C.: U.S. DHHS; 1997. (AHCPR Pub. No. 97-0065).
11. Akukwe C. The growing influence of non governmental organizations in international health: challenges and opportunities. J R Soc Health 1998;118:107-115.

12. Akukwe C, Hatcher BJ. Public health services: reducing infant mortality in the District of Columbia. Washington, D.C.: Office of Maternal and Child Health, D.C. Department of Health 1996.

13. Pan American Health Organization. Annual report of the director 1996, the director's message: healthy people, healthy spaces. Washington, D.C.: PAHO; 1996. (Official Document No. 283).

Manuscript received on 24 March 1998. Revised version accepted for publication on 5 February 1999. 
RESUMEN Este artículo plantea la necesidad de que los organismos que hacen donativos y los que los reciben escojan a ciertas comunidades para que participen en la conceptualización, el desarrrollo, la vigilancia y la ejecución de servicios de salud y programas en salud internacional. En el trabajo se presume que la mayor parte de las organizaciones que hacen donativos están radicadas en países industrializados. Teniendo en cuenta que los recursos tienen un límite tanto en los países en desarrollo como en los desarrollados, se repasa brevemente la tendencia actual hacia la disminución de los fondos del erario público disponibles para los sistemas de salud y la función cada vez más destacada que desempeñan en todo el mundo los servicios de salud financiados con capital privado. El artículo propugna establecer en las comunidades servicios de salud internacionales que reflejen las prioridades de las poblaciones objetivo. Además, contiene sugerencias prácticas para involucrar a las poblaciones locales en el planeamiento y la administración en salud internacional con base en la comunidad.

\section{Curso Latinoamericano de Posgrado en Micología}

Fechas: $\quad 23$ a 27 de agosto de 1999

Lugar: Buenos Aires, Argentina

El Instituto Nacional de Enfermedades Infecciosas, bajo la Administración Nacional de Laboratorios e Institutos de Salud de la Argentina "Dr. Carlos G. Malbrán", se complace en anunciar el Curso Latinoamericano de Micología Médica, donde se tratará el tema central de la resistencia a los antifúngicos en el laboratorio en sus aspectos teóricos y prácticos. Todos los participantes tendrán la oportunidad de aprender y practicar las técnicas más novedosas para la determinación de sensibilidad a los antifúngicos, incluso algunas que aún no han sido plenamente asimiladas en los países de América Latina. Este año se ha ampliado el número de laboratorios participantes con objeto de permitir una mayor difusión de conocimientos, iniciar una acción coordinada tendiente a la unificación de criterios, hacer uso óptimo de los recursos disponibles y reducir costos innecesarios como consecuencia del uso de métodos inadecuados.

Información:

Instituto Nacional de Enfermedades Infecciosas

"Dr. Carlos G. Malbrán"

Departamento de Micología

Av. Vélez Sarsfield 563

Buenos Aires (1281), Argentina

Teléfono y fax: 54-1-302-5066

Correo electrónico: Irodero@mail.retina.ar 